\title{
Investigations on the physical activity level of some Iranian drug suicidal patients
}

\author{
Maryam Hajain MD1, Shahram Mohaghegh MD²*, Latif Gachkar MD³ and Effat Barari ${ }^{4}$ \\ ${ }^{1}$ Community Medicine Specialist, Minimally Invasive Surgery Research Center, Iran University of Medical \\ Sciences, Tehran, Iran \\ ${ }^{2}$ Assistant Professor of Sports and Exercise Medicine, Clinical Research Development Center of Loghman \\ Hakim Hospital, Shahid Beheshti University of Medical Sciences, Tehran, Iran \\ ${ }^{3}$ Professor of Shahid Beheshti University of Medical Sciences, Tehran, Iran \\ ${ }^{4}$ Toxicological Research Center, Shahid Beheshti University of Medical Sciences, Tehran, Iran
}

\begin{abstract}
As it is important to use the preventive and therapeutic effects of exercise and physical activity in the management of suicidal patients, we primarily need to know physical activity level of suicidal patients. However there are little data in this topic. The females to male ratio of patients were about 2.1:1. with the average age of 29.7, minimum 13 and maximum 88 years, with standard deviation of 12.1. Physical activity level of majority (76.4 percent) of patients was in the range of low (less than 600 Metabolic equivalent/minute per week). Other variables except sex were not associated significantly with the physical activity level of patients. Physical activity level was significantly lower in females than males $(\mathrm{P}=0.001$, Chi square test). Low physical activity level and female sex are possible risk factors for drug suicidal attempts in Iranian patients.
\end{abstract}

KEY WORDS: EXERCISE, MENTAL HEALTH, PHYSICAL ACTIVITY, POISONING, SUICIDE

\section{INTRODUCTION}

Suicide is a global public health problem. Annually, almost 1 million people die in suicides worldwide (Turecki et al. 2015). The global suicide rate in 2008 was about 11.6 per 100,000. However, suicide has an increas-

\section{ARTICLE INFORMATION:}

*Corresponding Author: sh.mohaghegh@sbmu.ac.ir Received $27^{\text {th }}$ Nov, 2016

Accepted after revision $26^{\text {th }}$ Jan, 2017

BBRC Print ISSN: 0974-6455

Online ISSN: 2321-4007 CODEN: USA BBRCBA

;. Thomson Reuters ISI ESC and Crossref Indexed Journal

NAAS Journal Score 2017: 4.31 Cosmos IF: 4.006

- A Society of Science and Nature Publication, 2017. All rights reserved.

Online Contents Available at: http//www.bbrc.in/

DOI: $10.21786 / \mathrm{bbrc} / 10.3 / 14$ ing incidence and it is estimated to be for more than $2 \%$ of the global burden of disease by the year 2020 (Behmanehsh Poor et al. 2014). Demographic, social, and cultural factors can affect suicidal epidemiology (Mirhashemi et al. 2016). As suicide is condemned in Islam, the suicidal rate is low in most Islamic countries, 
yet it has shown to have increasing rate in recent years (Pritchard et al. 2007). According to the last WHO report, the reported suicide rates in Iran per 100,000 was 5.3 in both sexes: 3.6 in females and 7.0 in males (Mirhashemi et al. 2016) but figure nearly 2 times greater for average suicide rate $(9.9$ per 100,000$)$ was measured based on data elucidation (Hassanian-Moghaddam et al. 2017). Suicide and attempted suicide rates in Iran increased from 8.3 per 100,000 in 2001 to 19.4 in 2005 , then declined to 16.3 in 2007 (Saberi-Zafaghandi et al. 2012). However, the officially reported figures for suicide are lower than what really occurred (Malakouti et al. 2015). Suicide with drug and self-immolation are two most common reported methods of suicide in Iran (Nazarzadeh et al. 2013, Poorolajal et al. 2015).

Physical training and an active lifestyle have been used as major public health tools in the prevention and treatment of many physical diseases including cardiovascular and metabolic diseases (Peluso et al. 2005). Also, the effects of exercise on the brain, cognitive function, and behavior have been of interest (Deslandes 2014). Based on several epidemiological studies, it has been shown that exercise and physical activity can have preventive or delaying effects on the onset of different mental disorders, and also can be used as therapeutic tools solely or in adjunct with other treatments for mental disorders (Zschucke et al. 2013). About 90\% of individuals who had successful suicide had an identifiable psychiatric disorder before death (Arsenault-Lapierre et al. 2004) and at least $50 \%$ of suicide deaths are related to depressive episodes, either as major depressive disorder or bipolar disorder (Holma et al. 2014). In a Cochrane review which compared exercise intervention with no treatment, or with standard interventions (cognitive therapy and pharmacotherapy) in the management of depressive symptoms, a moderate clinical effect was found for exercise, which indicated that exercise was as effective as these standard treatments (Rimer et al. 2012). In a recent cross-sectional study which examined the relationship between suicidal thoughts (ST) and suicidal attempts (SA) and the level of physical activity (PA) among South Korean adolescents, there was an inverse dose-response relationship between the level of physical activity (defined as vigorous, moderate, and low) and ST and SA (Cho 2014). Also, in urban areas of the Iran, suicide is more common than rural areas (Shirazi et al. 2012). The cause of higher rate of suicide in cities may be related to lifestyle factors including more stress and lower physical activity level which can be the result of air pollution (Hajian et al. 2015).

Hajain et al. (2015) compared with those in rural areas. As it is important to use the preventive and therapeutic effects of exercise and physical activity in the management of suicidal patients, we primarily need to know physical activity level of suicidal patients in Iran.
There is no data on the physical activity level of suicidal patients in Iran. So, the aim of the present study was to investigate physical activity level of drug suicidal patients in a referral hospital of poisoning management in Tehran.

\section{MATERIAL AND METHODS}

In the current cross-sectional study, the Persian-translated long form interview-administered International Physical Activity Questionnaire (IPAQ) was used for assessing physical activity level of 406 drug suicidal patients who were admitted to poisoning ward of Loghman Hospital (the next morning after admission) between December 2014-April 2015. The validity and reliability of this version of IPAQ have already been proven in Iranian sample of individuals (VasheghaniFarahani et al. 2011). After obtaining the consent form, interview was conducted by an expert with alive drug suicidal patients who had good consciousness level and cooperation or with close relatives of the patients who were informed about the physical activity habits of the patients. The results were expressed as low (less than 600 metabolic equivalent (MET). minute per week), medium (between 600 to 3000 MET. minute per week), and high (more than 3000 MET. minute per week) level of physical activity. Also, the patients were asked about their age, weight, marital and educational statuses, number of children, absence or presence, and in this case, the type of background mental disorders, the history and the number of previous suicide attempt(s). The data was then analyzed using SPSS (v. 16) and related statistical tests (ANOVA test for quantitative and Chi square test for qualitative variables).

\section{RESULTS}

Totally, 406 patients were evaluated: 278 females $(68.4 \%)$ and 128 males (31.6\%) with the average age of 29.7, minimum 13 and maximum 88 years, with standard deviation of 12.1. The average weight of patients was 64.8 kilograms, minimum 37 and maximum 145 kilograms, with standard deviation of 15.6. Other epidemiologic characteristics of patients are provided in Table 1. A total of 310 patients (76.4\%) had low physical activity level, 80 patients (19.7\%) medium, and 16 patients (3.9\%) had high physical activity level. There were no significant differences in weight, number of children, and suicide history, marriage and educational status between patients with different physical activity levels ( $p$ value more than 0.05). There was significant difference in terms of different physical activity levels between the two sexes $(p$ value $=0.001)$, which means females in low 


\begin{tabular}{|c|c|c|c|}
\hline Variable & Description & Number & Percent \\
\hline \multirow{3}{*}{ Marriage status } & Single & 187 & 46.1 \\
\hline & Married & 202 & 49.8 \\
\hline & Divorce & 17 & 4.2 \\
\hline \multirow{3}{*}{$\begin{array}{l}\text { Number of } \\
\text { children }\end{array}$} & $0-1$ & 320 & 79 \\
\hline & $2-3$ & 71 & 17.5 \\
\hline & More than 3 & 15 & 3.5 \\
\hline \multirow{3}{*}{ Education } & Up to Diploma & 305 & 75.1 \\
\hline & Diploma to BSc & 86 & 21.1 \\
\hline & MSc and higher & 15 & 3.6 \\
\hline \multirow{7}{*}{$\begin{array}{l}\text { Mental disorder } \\
\text { (according } \\
\text { to patient's } \\
\text { statement) }\end{array}$} & No disease & 317 & 78.1 \\
\hline & Depression & 52 & 12.8 \\
\hline & Anxiety & 3 & .7 \\
\hline & Psychosis & 2 & .5 \\
\hline & Bipolar & 4 & 1.0 \\
\hline & Other & 20 & 4.9 \\
\hline & 0 & 245 & 60.3 \\
\hline \multirow{7}{*}{$\begin{array}{l}\text { History of } \\
\text { suicide }\end{array}$} & 1 & 70 & 17.2 \\
\hline & 2 & 15 & 3.7 \\
\hline & 3 & 14 & 3.4 \\
\hline & 4 & 5 & 1.2 \\
\hline & 5 & 4 & 1.0 \\
\hline & 6 & 3 & .7 \\
\hline & 7 & 1 & .2 \\
\hline
\end{tabular}

physical activity group had relatively higher percentage than their male counterparts and males in moderate and high physical activity groups had relatively higher percentage than their female peers.(Table 2).

\section{DISCUSSION}

According to the findings of the present study, from among 406 drug suicidal patients admitted to Loghman

Table 2. Physical activity levels of drug suicidal patients according to sex of them

\begin{tabular}{|c|c|c|c|c|c|c|}
\hline & & & \multicolumn{3}{|c|}{ Physical activity Level } & \multirow{2}{*}{ Total } \\
\hline \multirow{3}{*}{ Sex } & & & low & moderate & high & \\
\cline { 3 - 7 } & & & 224 & 49 & 5 & 278 \\
\cline { 2 - 7 } & male & & 86 & 31 & 11 & 128 \\
\cline { 3 - 7 } & & Percent & $80.6 \%$ & $17.6 \%$ & $1.8 \%$ & $100 \%$ \\
\hline \multirow{2}{*}{ Total } & & 310 & 80 & 16 & 406 \\
\hline & & Percent & $76.4 \%$ & $19.7 \%$ & $3.9 \%$ & $100.0 \%$ \\
\hline
\end{tabular}

Hospital, the majority (76.4\% percent) had low physical activity level. In a randomized cross over trial in highlevel suicide risk patients, regular endurance training in the form of mountain hiking was shown to reduce hopelessness, depression, and suicide ideation (Sturm et al. 2012). Moreover, the moderate level of evidence has been reported for the inverse dose-response relationship between mental disorders (depression and distress) and physical activity level in the latest guideline for exercise testing and prescription of American College of Sports Medicine (ACSM) (Ferguson 2014).

The mechanisms whereby exercise and physical activity induce positive psychological health are diverse and complex. Broadly, it can be divided into reducing stress response, minimizing excessive inflammation, and enhancing growth factor expression and neural plasticity. Physical fitness, achieved through regular exercise and/or spontaneous physical activity blunts stress reactivity, protects against potentially adverse behavioral and metabolic consequences of stressful events of life (Silverman et al. 2014).

Physical activity level of the patients of the preset study was measured by IPAQ includes both physical activity and exercise, i.e. a type of physical activity that is planned, structured, repetitive, and purposeful (Carek et al. 2011). Although much of the research on positive psychological effects of exercise has been done on aerobic exercise, resistance exercise or strength training can also induce many physiological and psychological advantages. Increase in cognition and self-esteem, and decrease in depression and anxiety after both singlebout sessions and long-term resistance training have been identified in growing body of literature (Strickland et al. 2014). Also there are evidences that indicate that outdoor physical activity interventions such as mountain hiking, stimulates higher positive and lower negative affective responses compared to an indoor physical activity condition(Niedermeier et al. 2017).

In our study, the majority (68.4 percent) of drug suicidal patients were female. Also, the female to male ratio was higher in low physical activity level group. These sexual differences have been seen in the previous studies (Esteghamati et al. 2011, Koohpayehzadeh et al. 2014), as well, and may be due to Iranian cultural and social backgrounds which encourage men to be more physically active compared with women.

The most common underlying mental disorder in our study was depression. Depression was also found in other studies as a risk factor for suicide and suicidal thought and self-destructive behavior in Iranian people (Ekramzadeh et al. 2012, Dabaghzadeh et al. 2015). It has been reported that the risk of suicide is increased by more than 50 percent in depressed individuals and it is about 20 times that of the general population in people 
with major depression (Baek et al. 2015). There is now compelling evidence that lifestyle factors including diet, physical activity and exercise, relaxation and meditative techniques, quality of sleep, environmental pollutants, and social support are significant in the pathogenesis and treatment of depression; moreover, epidemiological studies have shown that low physical activity can be a risk factor for the development of depressive symptoms and that regular physical activity in early years of life is linked with reduced risk of experiencing depression in adulthood (Sarris et al. 2014).

Therefore, prevention of depression and other mental disorders by doing regular physical activity and exercise is a cost-effective approach for people who experience higher rates of mental illness compared with the general population. Indeed, mandatory physical exercise for the prevention of mental illness has been proposed for medical students in USA (Bitonte et al. 2014) as high prevalence of depression and anxiety has been reported among USA and Canada medical students, with levels of overall psychological distress indicators consistently higher than that in the general population and age-matched peers (Dyrbye et al. 2006). This approach can be used in the public suicide prevention programs too, as exercise has been shown to improve stress management ability, general feelings of well-being, and self-esteem and can act as a nonspecific psychological therapy (Kaminsky et al. 2006).

\section{CONCLUSION}

Low physical activity level and female sex are possible risk factors for drug suicidal attempts in Iranian patients. More precisely designed studies are needed to evaluate the relationship between physical activity and suicidal attempts in females. Promotion of increasing physical activity and exercise for patients at risk of suicide especially females, are recommended.

\section{LIMITATIONS}

The study was done in a drug poisoning management center and suicidal patients with causes other than drug poisoning were not included. Also the cases were alive patients and the dead ones were not included.

\section{ACKNOWLEDGMENT}

The fund of this study was provided by research proposal number 4589 of Shahid Beheshti university of medical sciences, Clinical Research Development Center of Loghman Hakim Hospital.

\section{CONFLICT OF INTEREST}

There is no conflict of interest.

\section{REFERENCES}

Arsenault-Lapierre, G., Kim, C. Turecki, G. (2004).Psychiatric diagnoses in 3275 suicides: a meta-analysis.BMC Psychiatry 4: 37-37.

Baek, J. H., Park, J.-I., Ahn, J., Roh, S.-w., Heo, J.-Y., Fava, M., Mischoulon, D. Jeon, H. J. (2015).Review of Suicide Prevention Programs: Massachusetts, United States, in Comparison with Seoul.Psychiatry Investigation 12(3): 281-287.

Behmanehsh Poor, F., Tabatabaei, S. M. Bakhshani, N. M. (2014).Epidemiology of Suicide and its Associated Sociodemographic Factors in Patients Admitted to Emergency Department of Zahedan Khatam-Al-Anbia Hospital.Int J High Risk Behav Addict 3(4): e22637.

Bitonte, R. A. DeSanto, D. J., 2nd (2014).Mandatory physical exercise for the prevention of mental illness in medical students.Ment Illn 6(2): 5549.

Carek, P. J., Laibstain, S. E. Carek, S. M. (2011).Exercise for the treatment of depression and anxiety.Int J Psychiatry Med 41(1): 15-28.

Cho, K. O. (2014).Physical Activity and Suicide Attempt of South Korean Adolescents - Evidence from the Eight Korea Youth Risk Behaviors Web-based Survey.J Sports Sci Med 13(4): 888-893.

Dabaghzadeh, F., Jabbari, F., Khalili, H. Abbasian, L. (2015). Associated Factors of Suicidal Thoughts in HIV-Positive Individuals.Iran J Psychiatry 10(3): 185-191.

Deslandes, A. C. (2014).Exercise and Mental Health: What did We Learn in the Last 20 Years?Frontiers in Psychiatry 5: 66.

Dyrbye, L. N., Thomas, M. R. Shanafelt, T. D. (2006).Systematic review of depression, anxiety, and other indicators of psychological distress among U.S. and Canadian medical students. Acad Med 81(4): 354-373.

Ekramzadeh, S., Javadpour, A., Draper, B., Mani, A., Withall, A. Sahraian, A. (2012).Prevalence and correlates of suicidal thought and self-destructive behavior among an elderly hospital population in Iran.Int Psychogeriatr 24(9): 1402-1408.

Esteghamati, A., Khalilzadeh, O., Rashidi, A., Kamgar, M., Meysamie, A. Abbasi, M. (2011).Physical activity in Iran: results of the third national surveillance of risk factors of non-communicable diseases (SuRFNCD-2007).J Phys Act Health 8(1): 27-35.

Ferguson, B. (2014).ACSM's Guidelines for Exercise Testing and Prescription 9th Ed. 2014.The Journal of the Canadian Chiropractic Association 58(3): 328-328.

Hajain, M. Mohaghegh, S. (2015).Indoor air pollution in exercise centers.Int $\mathrm{J}$ medical toxicology and forensic medicine 5(1): 22-31.

Hassanian-Moghaddam, H. Zamani, N. (2017).Suicide in Iran: The Facts and the Figures from Nationwide Reports.Iranian Journal of Psychiatry 12: 5.

Holma, K. M., Haukka, J., Suominen, K., Valtonen, H. M., Mantere, O., Melartin, T. K., Sokero, T. P., Oquendo, M. A. Isometsa, E. T. (2014).Differences in incidence of suicide attempts between bipolar I and II disorders and major depressive disorder.Bipolar Disord 16(6): 652-661. 
Kaminsky, L. A. Medicine, A. C. o. S. (2006). ACSM's resource manual for guidelines for exercise testing and prescription, Lippincott Williams \&t Wilkins Baltimore, MD.

Koohpayehzadeh, J., Etemad, K., Abbasi, M., Meysamie, A., Sheikhbahaei, S., Asgari, F., Noshad, S., Hafezi-Nejad, N., Rafei, A., Mousavizadeh, M., Khajeh, E., Ebadi, M., Nakhjavani, M. Esteghamati, A. (2014).Gender-specific changes in physical activity pattern in Iran: national surveillance of risk factors of non-communicable diseases (2007-2011).Int J Public Health 59(2): 231-241.

Malakouti, S. K., Davoudi, F., Khalid, S., Ahmadzad Asl, M., Moosa Khan, M., Alirezaei, N., Mirabzadeh, A. DeLeo, D. (2015). The Epidemiology of Suicide Behaviors among the Countries of the Eastern Mediterranean Region of WHO: a Systematic Review.Acta Med Iran 53(5): 257-265.

Mirhashemi, S., Motamedi, M. H., Mirhashemi, A. H., Taghipour, H. Danial, Z. (2016).Suicide in Iran.Lancet 387(10013): 29.

Nazarzadeh, M., Bidel, Z., Ayubi, E., Asadollahi, K., Carson, K. V. Sayehmiri, K. (2013).Determination of the social related factors of suicide in Iran: a systematic review and meta-analysis. BMC Public Health 13: 4.

Niedermeier, M., Einwanger, J., Hartl, A. Kopp, M. (2017). Affective responses in mountain hiking-A randomized crossover trial focusing on differences between indoor and outdoor activity.PloS one 12(5): e0177719.

Peluso, M. A. Guerra de Andrade, L. H. (2005).Physical activity and mental health: the association between exercise and mood. Clinics (Sao Paulo) 60(1): 61-70.

Poorolajal, J., Rostami, M., Mahjub, H. Esmailnasab, N. (2015). Completed Suicide and Associated Risk Factors: A Six-Year Population Based Survey.Archives of Iranian Medicine 18(1): 39-43.

Pritchard, C. Amanullah, S. (2007).An analysis of suicide and undetermined deaths in 17 predominantly Islamic countries contrasted with the UK.Psychol Med 37: 421-430.
Rimer, J., Dwan, K., Lawlor, D. A., Greig, C. A., McMurdo, M., Morley, W. Mead, G. E. (2012).Exercise for depression.Cochrane Database Syst Rev 7: CD004366.

Saberi-Zafaghandi, M. B., Hajebi, A., Eskandarieh, S. Ahmadzad-Asl, M. (2012).Epidemiology of suicide and attempted suicide derived from the health system database in the Islamic Republic of Iran: 2001-2007.East Mediterr Health J 18(8): 836-841.

Sarris, J., O'Neil, A., Coulson, C. E., Schweitzer, I. Berk, M. (2014).Lifestyle medicine for depression.BMC Psychiatry 14: 107.

Shirazi, H. R., Hosseini, M., Zoladl, M., Malekzadeh, M., Momeninejad, M., Noorian, K. Mansorian, M. A. (2012).Suicide in the Islamic Republic of Iran: an integrated analysis from 1981 to 2007.East Mediterr Health J 18(6): 607-613.

Silverman, M. N. Deuster, P. A. (2014).Biological mechanisms underlying the role of physical fitness in health and resilience. Interface Focus 4(5): 20140040.

Strickland, J. C. Smith, M. A. (2014).The anxiolytic effects of resistance exercise.Frontiers in Psychology 5: 753.

Sturm, J., Ploderl, M., Fartacek, C., Kralovec, K., Neunhauserer, D., Niederseer, D., Hitzl, W., Niebauer, J., Schiepek, G. Fartacek, R. (2012).Physical exercise through mountain hiking in high-risk suicide patients. A randomized crossover trial.Acta Psychiatr Scand 126(6): 467-475.

Turecki, G. Brent, D. A. (2015).Suicide and suicidal behaviour. Lancet.

Vasheghani-Farahani, A., Tahmasbi, M., Asheri, H., Ashraf, H., Nedjat, S. Kordi, R. (2011).The Persian, last 7-day, long form of the International Physical Activity Questionnaire: translation and validation study.Asian J Sports Med 2(2): 106-116.

Zschucke, E., Gaudlitz, K. Ströhle, A. (2013).Exercise and Physical Activity in Mental Disorders: Clinical and Experimental Evidence.Journal of Preventive Medicine and Public Health 46(Suppl 1): S12-S21. 